compounds it would be important to know if prescribing practices were changing, albeit from a low baseline rate. Our data did not allow us to examine whether the use of new atypical drugs had changed over the two-year study period. However, we are currently conducting a prospective survey of the same sample which will allow us to determine if there has been any change in the use of new antipsychotics since our initial baseline survey described here.

It appears that the relatively low frequency of prescribing for each child psychiatrist makes it difficult to develop confidence and experience in the use of the new antipsychotics. Our results suggest that lack of clinical experience and training in psychopharmacology are more important reasons than a lack of published research evidence, or ideological resistance, for the infrequent prescribing of new antipsychotics by child and adolescent psychiatrists. The lack of use of new antipsychotics in adolescent inpatient units is a matter of concern, particularly if adolescents with severe, early-onset schizophrenia are being denied the potential benefits of new atypical antipsychotics.

\section{Acknowledgements}

We would like to thank the consultant child and adolescent psychiatrists in Trent for their interest and cooperation which made this survey possible.

\section{References}

BIRMAHER, B., BAKER, R., KAPUR, S., et al (1992) Clozapine for the treatment of adolescents with schizophrenia.
Journal of the American Academy of Child and Adolescent Psychiatry. 31, 160-164.

Campbell, M., Grega, D. M., Green, W. H., et al (1983) Neuroleptic induced dyskinesias in children. Clinical Neuropharmacology, 6, 207-222.

Green, W. H. PAdRon-Gayol, M. hardesty, A. S. et al (1992) Schizophrenia with childhood onset. Journal of the American Academy of Child and Adolescent Psychiatry. 31, 968-976.

JAMES, A. C. (1996) A survey of prescribing practises of child and adolescent psychiatrists. Child Psychology and Psychiatry Review. 1. 94-97.

KERWIN, R. (1994) The new atypical antipsychotics. A lack of extrapyramidal side-effects and new routes in schizophrenia research. British Journal of Psychiatry. 164, 141-148.

- (1996) An essay on the use of new antipsychotics. Psychiatric Bulletin, 20, 23-26.

KUMRA. S., Frazier. J. A., JacobSen, L. K., et al (1996) Childhood-onset schizophrenia. A double blind clozapine-haloperidol comparison. Archives of General Psychiatry. 53, 1090-1997.

Leiberman, J. A. SAFFerman, A. Z. POLlack, S. et al (1994) Clinical effect of clozapine in chronic schizophrenia: response to treatment and predictors of outcome. American Journal of Psychiatry, 151, 1744-1752.

LOWE, K. SMmTH, H. \& Clark, A. (1996) Neuroleptic prescribing in an adolescent psychiatric in-patient unit. Psychiatric Bulletin. 20. 538-540.

MOZEs, T. TOREN, P. ChERnAuzAN, N. et al (1994) Clozapine treatment in very early-onset schizophrenia. Joumal of the American Academy of Child and Adolescent Psychiatry. 33, 65-70.

* Karmen Slaveska, Specialist Registrar, Chris Hollis, Consultant and Senior Lecturer, and David Bramble, Consultant and Senior Lecturer. Department of Child and Adolescent Psychiatry. South Block, E Floor, Queen's Medical Centre, Nottingham NG7 $2 U H$

*Correspondence

\title{
Changes in practice of ECT: a follow-on study
}

\author{
Kate Trezise
}

Aims and method A retrospective case note study examining the effects of increased supervision on practice of electroconvulsive therapy (ECD).

Results Increasing the level of supervision of ECT sessions was associated with patients receiving on average almost two fewer treatment applications per course of ECT.

Clinical implications The risk of treatment is reduced because patients receive fewer anaesthetics, and they may be discharged home sooner. Such improvements in ECT practice should be relatively easily achievable in many ECT clinics.

In a previous study (Trezise \& Conlon, 1997), changes in practice of electroconvulsive therapy (ECT) over two successive years, before and after replacement of an Ectron Series 5 ECT machine 
by a Thymatron DGx, was described. Following the introduction of the Thymatron. patients received an average of 1.2 fewer treatments per course of ECT. To facilitate use of the new machine, consultant supervision of ECT sessions had been markedly increased, and it was therefore unclear to what extent the improved efficacy of ECT was due to increased supervision and training, rather than directly to the change of ECT machine.

I subsequently had the opportunity to attempt to separate these two factors when I moved to work in a different service. The second hospital was still using an Ectron Series 5 ECT machine at the time I started, and supervision and training of junior doctors performing ECT was below the level recommended by the Royal College of Psychiatrists (1995). It was therefore possible to increase the level of supervision of ECT sessions, and training of staff, while continuing to use the same ECT machine.

\section{The study}

Case notes were examined retrospectively for all patients receiving ECT in the year before increasing supervision of ECT sessions (Group 1) and for 11 months afterwards (Group 2). After 11 months a new ECT machine was purchased, and it was therefore impossible to extend the second part of the study to a full year. Thirty-one patients received ECT in the first group and 34 in the second group, from a catchment area of approximately 120000 . Information was gathered by discussion with colleagues and ECT clinic staff where it could not be obtained from the case notes and ECT record forms.

The following information was recorded for each patient: name, gender, in- or out-patient status, legal status during treatment, consultant, diagnosis, number of treatments received, previous ECT, medication, complications of treatment, energy settings used, mean motor fit length and outcome of treatment.

Diagnoses were determined from careful study of notes and discharge summaries. They were combined to give the following categories: primary depressive disorder, depressive disorder with a comorbid diagnosis and diagnoses other than depression (mainly mania and schizophrenia).

Medication was classified as follows: major tranquillisers, tricyclic antidepressants, other antidepressants, minor tranquillisers (including zopiclone), lithium and any other drugs.

Outcomes were determined from case notes, followed by discussion with staff where necessary. The outcomes on completion of treatment were used. Patients were categorised as recovered or markedly improved, or largely un- changed. No patients seemed to have deteriorated as a direct result of ECT.

Prior to introducing increased supervision of ECT, the consultant with responsibility for ECT attended treatment sessions approximately four to six times a year, usually following the changeover of junior doctors, so that there was little in the way of ongoing supervision or training. All patients were treated using a fixed energy setting on the machine, as recommended when the Ectron Series 5 was introduced (Ectron Ltd).

During the second half of the study, the consultant responsible for ECT and myself both attended the majority of sessions, with at least one of us being present on every occasion. In addition to direct supervision of ECT technique, we made decisions about the treatment settings to be used for each patient. and adjusted these as necessary to try and ensure that patients received adequate seizures at each treatment. while minimising adverse effects. We took note of medication, and discussed this with the patients' consultants when it appeared that prescribed medication might have been making ECT less effective.

\section{Findings}

The groups were not significantly different in terms of gender, age, in- or out-patient status, legal status, or history of previous ECT (see Table 1). Neither was there any significant difference between Group 1 and the equivalent group from the previous study, on any of these parameters (further details available from the author upon request).

There were no differences in diagnoses between the two groups. Four-fifths of the patients in each group were receiving ECT for a primary depressive disorder, with the diagnoses of the rest spread equally between the other two categories (Table 2).

There was no significant difference between the two groups in terms of any of the medication received during treatment, although there was a swing towards prescribing newer antidepressants instead of tricyclics for patients in the second group (see Table 2). The rate of complications

Table 1. Demographic data

\begin{tabular}{|c|c|c|c|}
\hline & $\begin{array}{l}\text { Group I } \\
\text { (unsupervised) }\end{array}$ & $\begin{array}{l}\text { Group } 2 \\
\text { (supervised) }\end{array}$ & $\mathbf{P}<x^{2}$ \\
\hline $\begin{array}{l}\text { Total patients } \\
\text { Mean age (year) } \\
\text { Female } \\
\text { In-patients } \\
\text { Informal patients } \\
\text { Previous ECT }\end{array}$ & $\begin{array}{l}31(100 \%) \\
57.4 \\
16(52 \%) \\
30(97 \%) \\
22(71 \%) \\
22(71 \%)\end{array}$ & $\begin{array}{l}34(100 \%) \\
58.0 \\
20(59 \%) \\
28(82 \%) \\
28(82 \%) \\
18(53 \%)\end{array}$ & $\begin{array}{l}- \\
\text { NS' } \\
\text { NS } \\
\text { NS } \\
\text { NS } \\
\text { NS }\end{array}$ \\
\hline
\end{tabular}

1. P<t-test (not $\left.\chi^{2}\right)$ 
Table 2. Diagnoses, medication, complications and outcome

\begin{tabular}{lccc}
\hline & $\begin{array}{l}\text { Group I (unsupervised) } \\
n=31\end{array}$ & $\begin{array}{l}\text { Group 2 (supervised) } \\
n=34\end{array}$ & $P_{<\chi^{2}}$ \\
\hline $\begin{array}{l}\text { Diagnosis } \\
\text { Depressive disorder }\end{array}$ & $25(80 \%)$ & $28(82 \%)$ & NS \\
Depression and comorbid diagnosis & $3(10 \%)$ & $4(12 \%)$ & NS \\
Other diagnosis & $3(10 \%)$ & $2(6 \%)$ & NS \\
Medication & $18(58 \%)$ & $15(44 \%)$ & NS \\
Tricyclic antidepressant & $7(23 \%)$ & $14(41 \%)$ & NS \\
Other antidepressant & $8(23 \%)$ & $4(12 \%)$ & NS \\
Complications & $25(81 \%)$ & $25(74 \%)$ & NS \\
Outcome & $6(19 \%)$ & $9(26 \%)$ & \\
Recovered/improved & & & \\
No change & &
\end{tabular}

(mainly confusion or memory loss) was not significantly different between the two groups. Neither was there any difference in outcomes, with 81 and $74 \%$ respectively being recovered or clearly improved (see Table 2).

A clear difference was apparent, however, when considering the number of treatments per course received by patients in the two groups. Patients in the group whose treatment was relatively unsupervised needed on average 8.40 (s.d.=3.44) treatments before their responsible consultants decided to discontinue ECT. Those in the group whose treatment was closely supervised received on average 6.52 (s.d.=3.44) treatments per course, a difference of 1.88 treatments $(P<0.03 t$-test $)$.

\section{Comment}

As in the previous study, diagnoses were not operationally defined, nor were any objective criteria used to measure the severity of initial illness or outcome of treatment. It is therefore difficult to be certain that the two groups were directly comparable. Another limitation of the present study is that the groups were relatively small.

However, the substantial reduction in the number of treatments received per course for patients in the second group is significant, and this was achieved without affecting the outcome of treatment. In fact a greater reduction was achieved than in the initial study. The number of treatments received by the unsupervised group in this study was perhaps artificially increased by two patients, who received 15 and 16 treatments respectively, hence a bigger difference may have been apparent following introduction of supervision.

Decisions about prescribing and stopping ECT were made by the consultants in charge of the patients, and there was nothing to suggest that their practice had altered during the period of this study. It is therefore unlikely that the results were biased by treatment being prematurely terminated.

The tendency for more patients to be receiving newer antidepressants may have had some bearing on the efficacy of ECT in the second half of the study. Both tricyclic antidepressants and selective serotonin reuptake inhibitors reduce seizure threshold (Markowitz \& Brown, 1987; Feighner \& Boyer, 1991) but it is unclear if this difference is more marked in either group, or for individual drugs. It is therefore difficult to know whether prescribed medication may have affected the outcome of the study.

It seems likely that increasing the level of supervision of treatment sessions played a substantial part in the increased efficacy of ECT. There are several ways in which supervision may be of benefit during ECT. The first is direct hands on supervision of the technique of junior doctors administering ECT. Paying detailed attention to electrode position and contact, as well as the way in which the treatment machine is used, ensures maximum efficiency of individual treatments.

It is also important to pay attention to concurrent psychotropic medication. Many psychiatric patients receive benzodiazepines which are a useful short term adjunct to antidepressants in acutely ill patients (British National Formulary, Number 33, March 1997). In this study $23 \%$ of patients in Group 1 and $15 \%$ of patients in Group 2 were receiving benzodiazepines at the time of undergoing ECT. Benzodiazepines have an anticonvulsant action, and reduce both seizure duration (Strömgren et al, 1980) and the therapeutic effect of ECT when administered the night prior to treatment (Pettinati, 1990). Some patients were also receiving carbamazepine, and it is likely that this also affects seizure threshold (Royal College of Psychiatrists, 1995). The role of the senior doctor supervising ECT sessions is to note any medication which may affect ECT, to suggest alterations where these are clinically feasible, and to adjust 
the stimulus intensity where necessary to compensate for effects of medication.

A third way in which supervision of ECT sessions may be beneficial is in helping to make decisions about restimulating patients when doubtful seizures have been achieved, and adjusting dosage settings at subsequent treatments. It is not easy to do this effectively without being present at the majority of sessions, and observing the response of patients to treatment.

The doctor who supervises ECT also has a more general role in educating medical and other groups of staff about correct use of ECT, and drawing up protocols for use in the ECT clinic. The Royal College of Psychiatrists (1995) recommend that dedicated time be provided to perform these duties.

I do not doubt the superiority of newer ECT machines such as the Thymatron DGx in allowing ECT to be more flexibly tailored to individual needs, in treating patients with higher convulsive thresholds and in allowing closer monitoring of treatment. This study shows, however, that it is possible to improve the delivery of ECT substantially by carefully supervising and monitoring the use of existing equipment.

\section{Acknowledgements}

I thank Dr Agnès Nalpas, Patrick Dwyer and the other members of the ECT team whose commit- ment and enthusiasm enabled this work to take place.

\section{References}

FEIGHNER, J. P. \& BOYER, W. F. (1991) Selective Serotonin Reuptake Inhibitors: The Clinical Use of Citalopram. Fluoxetine, Fluvaxamine, Paraxetine and Sertraline. Chichester: John Wiley.

MARKOWITZ, J. C. \& BROWN, R. P. (1987) Seizures with neuroleptics and antidepressants. General Hospital Psychiatry, 9, 135-141.

Pettinati, H. M., STEPhenS, S. M., Willis, K. M., et al (1996) Evidence for less improvement in depression in patients taking benzodiazepines during unilateral ECT. American Journal of Psychiatry, 147, 1029-1035.

ROYAL COLLEGE OF PSYCHIATRISTS (1995) The ECT Handbook (Council Report CR39). London: Royal College of Psychiatrists.

STRÓMGREN, L., DAHL, J., FJELDBEg, N., et al (1980) Factors influencing seizure duration and number of seizures applied in unilateral electroconvulsive therapy. Acta Psychiatrica Scandinavica, 62, 158-165.

TREZISE. K. \& CONLON. B. (1997) Effects of changes in practice of electroconvulsive therapy over a two year period. Psychiatric Bulletin, 21, 10-12.

Kate Trezise, Specialist Registrar in Learning Disability Psychiatry, Ridge Hill Hospital, Brierley Hill Road, Wordsley, Stourbridge, West Midlands

\title{
Proposed change in service delivery and stress among nursing staff
}

\author{
Ajit Shah and Tamal De
}

Aims and method The impact of major organisational change in a psychogeriatric service was examined in a naturalistic and opportunistic study, which was prospectively conducted.

Results A positive association between the organisational change of the proposed closure and relocation of a psychogeriatric ward and stress among the nursing staff as measured by the General Health Questionnaire was demonstrated.

Clinical implications Policy-makers, purchasers and providers need to consider the implication of such stress and develop strategies to minimise stress prior to any major policy change.
The provision of health services is constantly evolving to incorporate legislative changes, economic factors and scientific developments. Several recent legislative changes in the National Health Service (NHS), including the NHS and Community Care Act 1990, have resulted in major changes in health service provision. The impact of such changes on NHS staff has been poorly examined. Nursing staff left behind in large psychiatric hospitals during deinstitution-alisation experience burn-out, poor morale and stress (Lamb, 1977; Mendal, 1979). The closure of a continuing care psychogeriatric ward, initiated by the local NHS 